\title{
O que determina o número de candidatos em uma eleição?
}

Mauro Rodrigues*

O interesse de economistas em questões políticas vem crescendo rapidamente nos últimos anos. Em particular, pergunta-se porque certas eleições possuem mais candidatos que outras. Por exemplo, em 2004, 14 pessoas apresentaram candidatura para prefeito na eleição de primeiro turno em São Paulo; no mesmo ano, um único candidato concorreu (e venceu) a eleição de Bom Jardim da Serra (SC).

A pesquisa acadêmica sobre o tema apresenta duas principais explicações. A primeira enfatiza que a estrutura institucional determina o número de candidatos. Por exemplo, a presença de eleições diretas em um único turno tenderia a reduzir a entrada de candidatos. Esta é uma justificativa frequentemente mencionada para a persistência de eleições com apenas dois candidatos para a presidência dos Estados Unidos. Por outro lado, pleitos em que há possibilidade de segundo turno - como nas eleições para governador e presidente no Brasil - atrairiam um número maior de competidores.

Uma segunda linha de pesquisa enfatiza a heterogeneidade social como explicação para o número de candidatos. Mais especificamente, a presença de grupos distintos em uma sociedade (por exemplo, por conta de diferenças raciais, religiosas ou de renda) motivaria o aparecimento de representantes políticos para cada um destes grupos. Sociedades mais homogêneas, desta forma, apresentariam poucos candidatos por eleição.

Pesquisadores têm testado estas teorias, utilizando principalmente dados de eleições presidenciais de diversos países. Em geral, conclui-se que uma mistura destas duas teorias explica relativamente bem as diferenças no número de candidatos entre países. Mais especificamente, uma maior heterogeneidade social tenderia a produzir mais candidatos, porém somente em sociedades com eleições em dois turnos. Isto levou diversos acadêmicos a argumentar que este sistema permitiria uma maior representatividade, em eleições democráticas, aos diversos grupos de uma sociedade.

O principal problema destes estudos está na possibilidade de os países determinarem suas próprias regras eleitorais. Por exemplo, uma elite política forte (por si só um fator que limita o número de candidatos) poderia manipular o sistema eleitoral de modo a dificultar a entrada de novos competidores políticos. Em outras palavras, o uso de dados de países não

\footnotetext{
* Doutor em Economia pela Universidade da Califórnia. É professor da Faculdade de Economia, Administração e Contabilidade da Universidade de São Paulo. Endereço eletrônico: mrodrigues@usp.br.
} 
permite responder a seguinte pergunta: as regras eleitorais são realmente um fator causal do número de candidatos? Ou a relação encontrada entre estas duas variáveis trata-se apenas de uma correlação?

O caso brasileiro, por outro lado, oferece oportunidade única para entender esta relação. A Constituição de 1988 determinou que os municípios com mais de 200 mil eleitores passassem a ter eleições para prefeito em dois turnos; os demais municípios continuariam com turno único. Este é o tema da pesquisa que desenvolvo no momento com os professores Carlos Eduardo Gonçalves e Ricardo Madeira, ambos também da FEA/USP. Diferentemente dos estudos acima mencionados, ao focar em municípios, eliminamos a possibilidade de manipulação da regra eleitoral. Além disso, possuímos informações de eleições em diversos municípios, tanto antes como depois da implementação na nova regra, o que permite uma identificação mais clara dos efeitos do sistema de dois turnos.

Utilizamos, como medida de heterogeneidade social, um índice de desigualdade de renda (o índice de Gini) de um município. Nossos resultados corroboram a evidência internacional, ou seja: o sistema em dois turnos tende a elevar o número de candidatos somente em municípios em que a heterogeneidade é suficientemente alta. 